\title{
Cognitive benefits of exercise interventions: an fMRI activation likelihood estimation meta-analysis
}

\author{
Qian $\mathrm{Yu}^{1} \cdot$ Fabian Herold ${ }^{2} \cdot$ Benjamin Becker ${ }^{3} \cdot$ Ben Klugah-Brown ${ }^{3} \cdot$ Yanjie Zhang $^{1} \cdot$ Stephane Perrey $^{4} \cdot$ \\ Nicola Veronese ${ }^{5} \cdot$ Notger G. Müller ${ }^{2} \cdot$ Arthur F. Kramer $^{6,7} \cdot$ Liye Zou $^{1}$
}

Received: 27 November 2020 / Accepted: 26 February 2021 / Published online: 6 March 2021

(c) The Author(s), under exclusive licence to Springer-Verlag GmbH Germany, part of Springer Nature 2021

\begin{abstract}
Despite a growing number of functional MRI studies reporting exercise-induced changes during cognitive processing, a systematic determination of the underlying neurobiological pathways is currently lacking. To this end, our neuroimaging meta-analysis included 20 studies and investigated the influence of physical exercise on cognition-related functional brain activation. The overall meta-analysis encompassing all experiments revealed physical exercise-induced changes in the left parietal lobe during cognitive processing. Subgroup analysis further revealed that in the younger-age group ( $<35$ years old) physical exercise induced more widespread changes in the right hemisphere, whereas in the older-age group ( $\geq 35$ years old) exercise-induced changes were restricted to the left parietal lobe. Subgroup analysis for intervention duration showed that shorter exercise interventions induced changes in regions connected with frontoparietal and default mode networks, whereas regions exhibiting effects of longer interventions connected with frontoparietal and dorsal attention networks. Our findings suggest that physical exercise interventions lead to changes in functional activation patterns primarily located in precuneus and associated with frontoparietal, dorsal attention and default mode networks.
\end{abstract}

Keywords Exercise $\cdot$ Cognition $\cdot$ Brain health $\cdot$ Network

Qian Yu and Fabian Herold have contributed equally to this work.

Liye Zou

liyezou123@gmail.com

Qian Yu

yuqianmiss@163.com

Fabian Herold

Fabian.herold@dzne.de

Benjamin Becker

ben_becker@gmx.de

Ben Klugah-Brown

bklugah@gmail.com

Yanjie Zhang

elite_zhangyj@163.com

Stephane Perrey

stephane.perrey@umontpellier.fr

Nicola Veronese

ilmannato@gmail.com

Notger G. Müller

notger.mueller@dzne.de

Arthur F. Kramer

a.kramer@northeastern.edu
1 Exercise and Mental Health Laboratory, School of Psychology, Shenzhen University, Shenzhen 518060, China

2 Research Group Neuroprotection, German Center for Neurodegenerative Diseases (DZNE), Leipziger Str. 44, 39120 Magdeburg, Germany

3 The Clinical Hospital of Chengdu Brain Science Institute, MOE Key Laboratory for Neuroinformation, University of Electronic Science and Technology of China, Chengdu 610054, Sichuan, China

4 EuroMov Digital Health in Motion, Univ Montpellier, IMT Mines Ales, Montpellier, France

5 Primary Care Department, Azienda ULSS 3 (Unità Locale Socio Sanitaria) Serenissima, Dolo-Mirano District, Venice, Italy

6 Center for Cognitive and Brain Health, Department of Psychology, Northeastern University, Boston, MA 02115, USA

7 Beckman Institute, University of Illinois At Urbana-Champaign, Champaign, IL 61801, USA 


\section{Introduction}

Cognition covers a wide range of mental abilities that allow us to perceive, process and store information (Bostrom 2009; Herold et al. 2018) although no uniform definition has yet been reached (Allen 2017; Bayne et al. 2019). Consequently, cognitive performance is crucial to successfully interact with our environment and thus determine several aspects of successful everyday life functioning (MacNeill and Lichtenberg 1997; Salthouse 2011). Notably, there is increasing evidence in the literature showing that specific cognitive abilities such as processing speed and episodic memory gradually decline with aging (Harada et al. 2013; Hedden and Gabrieli 2004; Park et al. 2002; Salthouse 2011), and poor cognitive performance leads to impairments in several aspects of everyday life, including walking, financial management, and driving (Cohen et al. 2016; Montero-Odasso et al. 2012; Morris et al. 2016). Moreover, poorer cognitive performance has been shown to predict neurological diseases such as dementia (Boraxbekk et al. 2015) and has been associated with a higher mortality risk (Shipley et al. 2006). It is thus of general importance to preserve cognitive functions across the lifespan and particularly in aging populations.

Current approaches to preserve cognitive functions in the aging population focus on lifestyle changes and emphasize the role of regular physical activity and exercise (Bherer et al. 2013; Hillman et al. 2008; Kivipelto et al. 2018; Liu-Ambrose et al. 2018). An increase in physical activity level is usually achieved through regular physical exercise (also referred to as physical training). Indeed, accumulating evidence indicates that both acute bout of physical exercise (Chang et al. 2012; Ludyga et al. 2016; Pontifex et al. 2019) and chronic physical exercise intervention (hereafter referred to as physical training) (Falck et al. 2019; Ludyga et al. 2016) can influence cognitive performance positively. However, the underlying neurobiological processes which lead to an increase in cognitive performance after physical interventions are not fully understood.

According to Stillman (Stillman et al. 2016), physical exercise interventions induce changes on different levels of analysis which, in turn, promote the improvement of cognitive performance. In particular, physical exercise and physical training lead to changes on (i) molecular and cellular levels (e.g., brain-derived neurotrophic factors); (ii) structural and/or functional levels (e.g., hippocampus volume and hippocampal activity), and (iii) socioemotional level (e.g., sleep quality, well-being, self-efficacy) (Stillman et al. 2016). Currently, there are systematic reviews and meta-analysis available which summarize the beneficial effects of acute physical exercise (a single bout of exercise) on changes: (i) molecular and cellular level (i.e., brain-derived neurotrophic factor) (Coelho et al. 2013; de Assis and de Almondes 2017; Dinoff et al. 2017; Knaepen et al. 2010); (ii) structural level (Chen et al. 2020; Zheng et al. 2019) and (iii) socioemotional level (i.e., sleep) (Kelley and Kelley 2017; Kovacevic et al. 2018). In contrast, the effects of physical exercise on functional brain changes that accompany acute physical exercise and physical training are currently less well understood. In this context, previous qualitative reviews have summarized the effects of acute physical exercises (Herold et al. 2020) and physical training (Herold et al. 2019; Voelcker-Rehage 2013) on functional brain changes, but did not perform a systematic quantitative meta-analyses. Moreover, given that some theories of cognitive aging emphasize the importance of compensatory brain activation patterns in distinct functional neural networks (Park and Reuter-Lorenz 2009; ReuterLorenz and Park 2014), a deeper understanding of physical exercise-induced functional brain activation changes can help us to better tailor physical exercise interventions to individuals. Hence, this meta-analysis addresses this gap in the literature and investigates the influence of physical exercise interventions on cognition-related changes of functional brain activation.

\section{Methods}

This study followed the recommendations outlined in the Preferred Reporting Items for Systematic Review and MetaAnalysis (PRISMA) guidelines and has been registered on OSF Registries (Registration https://doi.org/10.17605/OSF. IO/674HF).

\section{Data sources}

The literature search was conducted on April 19th, 2020, through four electronic databases (Pubmed, Web of Science, PsycINFO, and Embase). Search terms related to the object of this meta-analysis (for details see the supplementary material 1) were used to identify eligible studies based on a search in title and abstract. Furthermore, reference lists of included articles were manually searched for relevant articles that were captured through the database searches.

\section{Inclusion criteria and study selection}

The screening for relevant studies was conducted adhering to the PICOS-principles which stands for participants $(\mathrm{P})$, intervention $(\mathrm{I})$, comparisons $(\mathrm{C})$, outcomes $(\mathrm{O})$, and study design (S) (Harris et al. 2014; Moher et al. 2009). We included peer-review journal article published in English when they met the following inclusion criteria: $(\mathrm{P})$ no 
restrictions were applied and we included all age groups regardless of pathologies; (I) only studies performing physical exercise/physical training were considered as eligible; (C) only studies with a pre/post-intervention experimental designs and at least one group assigned to physical exercise/ physical training intervention were included; $(\mathrm{O})$ the relevant studies needed to assess cognition-related brain activation patterns via fMRI, PET or SPECT (task-based imaging studies) and needed to report retrievable data in standard Talairach or Montreal Neurologic Institute (MNI) coordinates; (S) we included interventional studies, but excluded cross-sectional studies. Based on the above-mentioned inclusion criteria, two independent researchers (QY and LZ) first screened article titles and abstracts to identify eligible articles. Afterwards and as recommended, a more detailed screening using the full-text of the article was conducted to ensure that all inclusion criteria were met.

\section{Data extraction}

The extraction of the relevant data was performed by two independent reviewers (QY and LZ) and the following information were extracted: (i) name of the lead author; (ii) imaging modality; (iii) population characteristics (e.g., health status and age); (iv) intervention characteristics (e.g., the number of participants, type of physical exercise, exercise duration, exercise intensity, training frequency, training duration, and control condition); (v) cognitive task paradigms employed to assess the effects of the intervention, and (vi) functional brain activation results (e.g., the number of foci). Risk of bias was independently assessed (by QY and LY) using the PEDro scale including 11 items (de Morton 2009).

\section{Activation likelihood estimation (ALE)}

ALE is a coordinate-based meta-analytical method that has been used to determine the consistent locations of brain activation in included studies that use similar experimental conditions. In ALE, activation foci are regarded as probability distributions centered on the reported coordinates. ALE maps are constructed after calculating each space voxel's likelihood to be activated. The null-distributions acquired from independent studies' ALE values is usually used to test the reliability of ALE map and this process have similarities with permutation test across experiments. The contribution of each study is weighted by its sample size, and each study is considered as a random effect. The observed values in the ALE distribution are compared to the null distribution in order to assign probability estimates to the observed experimental data. For ALE meta-analysis, Eickhoff et al. (2016) recommended that 17 or more experiments are needed to control excessive contribution of a single experiment for the cluster-level thresholding; and 14 experiments are necessary for voxellevel thresholding (Eickhoff et al. 2016). Usually, each study will include one or more experiments; each experiment only includes the foci in the same condition (i.e., activation status, intervention type).

In this study, we performed ALE analyses with GingerALE v3.0.2 (http://www.brainmap.org/ale/) (Eickhoff et al. 2009) in MNI space, and cluster-based family-wise error (FWE) was used with a threshold of $p<0.05$ (permuted 1000 times) (Eickhoff et al. 2009). The $p$-value accounts for the proportion of the random spatial relation between the various experiments under the null distribution. Coordinates reported in Talairach space in the original studies were initially transformed to the MNI space using the Lancaster transform icbm2tal software procedure as implemented in the Convert Foci tool of GingerALE (Laird et al. 2010). The ALE maps were imported into Mango Version 4.1 (http:// ric.uthscsa.edu/mango/mango.html) software and overlaid on an anatomical template in MNI space for visualization and comparison.

\section{Anatomical connectivity, functional connectivity and functional characterization of the identified brain regions}

In this study, if a meta-analytic identified cluster included more than one peak, we considered the area where the peak was centered at as sub-region (radius $=3 \mathrm{~mm}$ ). Anatomical and functional connection patterns of each sub-region were further determined by the Brainnetome Atlas and visualized by the Brainnetome Atlas Viewer (V1.0) (Fan et al. 2016; Liu et al. 2013). The functional characterizations of each sub-region are illustrated through probabilistic maps reflecting the behavioral domain and paradigm class according to meta-data labels of the BrainMap database (http:// www.brainmap.org/taxonomy). Overlapping behavioral domain(s) or paradigm(s) across sub-regions were subsequently selected (Fan et al. 2016; Liu et al. 2013). Brainnetome Atlas offers a fine-grained and cross-validated atlas providing structural information of more than 200 subregions. Brainnetome Atlas also maps the brain structure and function to mental processes by reference to the BrainMap database. Thus, Brainnetome Atlas provides an effective way for researchers to explore the complex relationship between anatomy, connectivity and function.

We also used the DPABI, a surface-based fMRI data analysis toolbox, to explore associations between regions/subregions identified in both overall and subgroup analyses and the 7 networks proposed by Yeo et al. (Yan et al. 2016; Yeo et al. 2011). DPABI yoked between images were obtained from ALE analysis and DPABI template. 


\section{Subgroup analysis}

Given that physical exercise-induced changes on the brain functional and behavioral level might be influenced by both individual characteristics (e.g., health status, age and regular level of physical activity) and intervention characteristics (e.g., training duration), the included studies were categorized into the following subgroups (as recommended by previous reviews Piercy et al. 2018; Stillman et al. 2020)): (i) health status (healthy vs. patients) - the patient groups included studies conducted in individuals with social anxiety disorder, major depressive disorder, cognitive impairment, fibromyalgia, Parkinson's disease, and bipolar disorder; (ii) age ("younger-age group: $<35$ years old" vs "olderage group: $\geq 35$ years old"). The cut-off of 35 years was employed to achieve a relatively balanced number of studies for each age-related subgroup analysis and was additionally based on evidence that cognitive function typically peaks around 35 years (Hartshorne and Germine 2015); (iii) training duration ("shorter-term: $<12$ weeks" vs "longerterm: $\geq 12$ weeks"). Based on previous meta-analysis, we used a 12-week training duration as the cut-off point for subgroup analysis (Piercy et al. 2018); (iv) although physical activity is characterized by three important components (intensity, frequency, and duration), it is reported that total amount of physical activity (i.e., minutes of exercise per week) is the most important factor for achieving health benefits (Piercy et al. 2018). Hence, weekly total minutes of exercise were used to categorize studies into two groups, including physically inactive group (PIG) and physically active group (PAG). Specifically, we followed the criteria from the Physical Activity Guidelines for Americans (2nd Edition) to determine the group of each experiment-based study with the age-specific cut-off values: (a) $180 \mathrm{~min}$ per week in children and adolescents aged 6 to 17 years (PIG: $<180$ min per week; PAG: $\geq 180$ min per week); (b) 150 min (moderate-intensity aerobic exercise) per week in adults (PIG: $<150$ min per week; PAG: $\geq 150$ min per week). Notably, individuals aged over 65 years who kept on exercising were considered as physically active, as suggested by the aforementioned guideline (Piercy et al. 2018).

\section{Data and code availability statement}

This ALE analysis was conducted with GingerALE v3.0.2 (http://www.brainmap.org/ale/) and Mango Version 4.1 (http://ric.uthscsa.edu/mango/mango.html) software were used for presentation. Anatomical and functional connection patterns of each sub-region were further determined by the Brainnetome Atlas (http://atlas.brainnetome.org/) and visualized by the Brainnetome Atlas Viewer (http://atlas .brainnetome.org/download.html). DPABI software (http:// rfmri.org/dpabi) was used to explore associations among identified regions/sub-regions. Study data used for the metaanalysis are provided in Table 1.

\section{Results}

\section{Study selection}

The systematic literature search returned a total of 42,302 records and 7870 duplicates were removed (see Fig. 1). The remaining 34,432 records were initially screened by examining the article titles and abstracts, with 34,195 records being excluded due to their failure to meet the pre-determined inclusion criteria (e.g., no original research or case reports, no cognition-related outcomes). Full-text assessment of 237 was further conducted by two independent authors (QY and LZ), which resulted in 20 eligible studies (26 experiments); as shown in Fig. 1, 1217 records were excluded according to our selection criteria (review and conference abstract $=24$, no pre-to-post imaging assessment $=10$, no cognition-related outcomes $=168$, no coordinates of whole-brain analysis $=3$, non- $\operatorname{cognitive}$ task $=2$; non-exercise intervention $=10$ ).

\section{Characteristics of included studies}

There are 260 foci of activation within 20 studies including a total 745 participants with mean age of $47.41(\mathrm{SD}=22.04)$ : 283 patients (mean age $=44.01, \mathrm{SD}=20.28$ ) and 463 healthy people (mean age $=49.49, \mathrm{SD}=22.83$ ). Study characteristics are detailed in Table 1.

\section{Overall analysis: exercise-induced brain activation associated with cognition}

Twenty studies that investigated the effects of physical exercise on cognition-associated functional brain activation were included in this meta-analysis (Baeck et al. 2012; Boa Sorte Silva et al. 2020; Chen et al. 2016; Duchesne et al. 2016; Goldin et al. 2012; Gourgouvelis et al. 2017; Hsu et al. 2018; Krafft et al. 2014; Li et al. 2019; Liu-Ambrose et al. 2012; Martinsen et al. 2018; Metcalfe et al. 2016; Nishiguchi et al. 2015; Pensel et al. 2018; Schmitt et al. 2019; Smith et al. 2013; Wagner et al. 2017; Wriessnegger et al. 2014; Wu et al. 2018). Overall, 260 foci from all 26 experiments converged onto a $2200 \mathrm{~mm}^{3}$ cluster centered at $(-26.2,-57.9$, 45.3) with 4 peaks (Fig. 2a). All 4 peaks were located at the parietal lobe of left cerebrum. More specifically, the cluster encompassed regions in the precuneus $(69.7 \%)$, inferior parietal lobule (27.3\%), and superior parietal lobule (3\%) and covered regions the following Brodmann areas 7, 19, 39 , and 40.

Examining the direction of the effects in terms of increased activation, 184 foci from 17 experiments were 


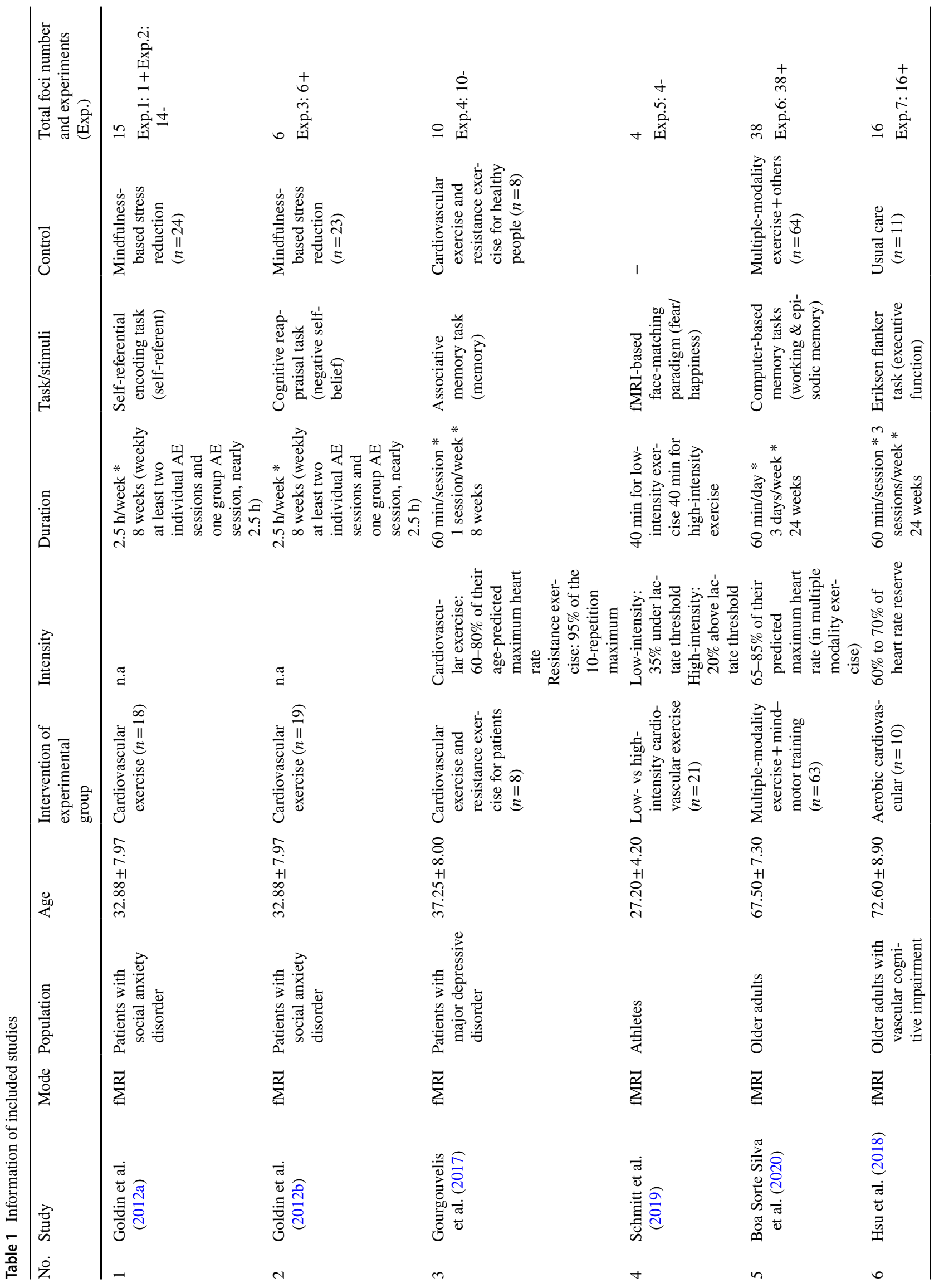




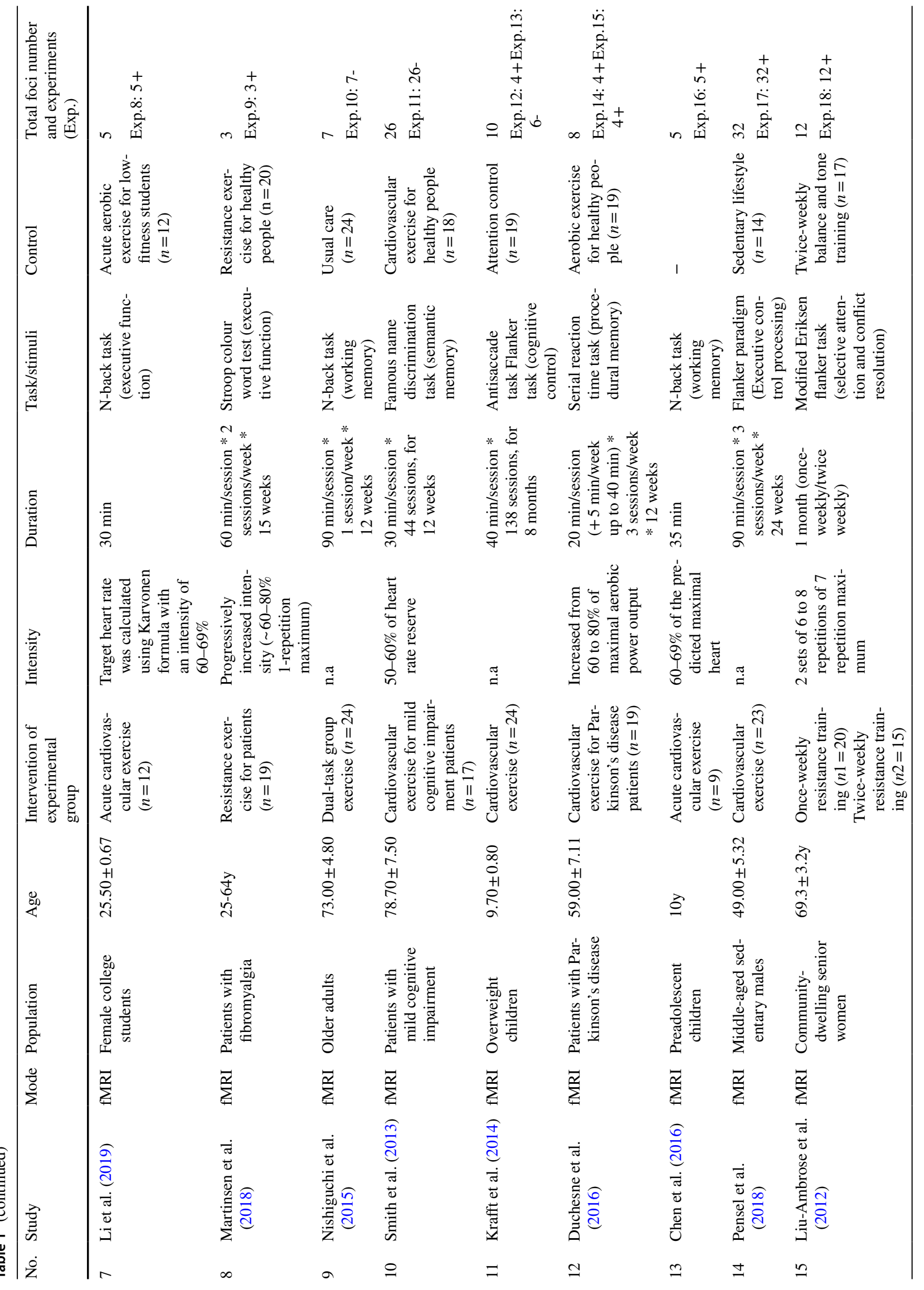




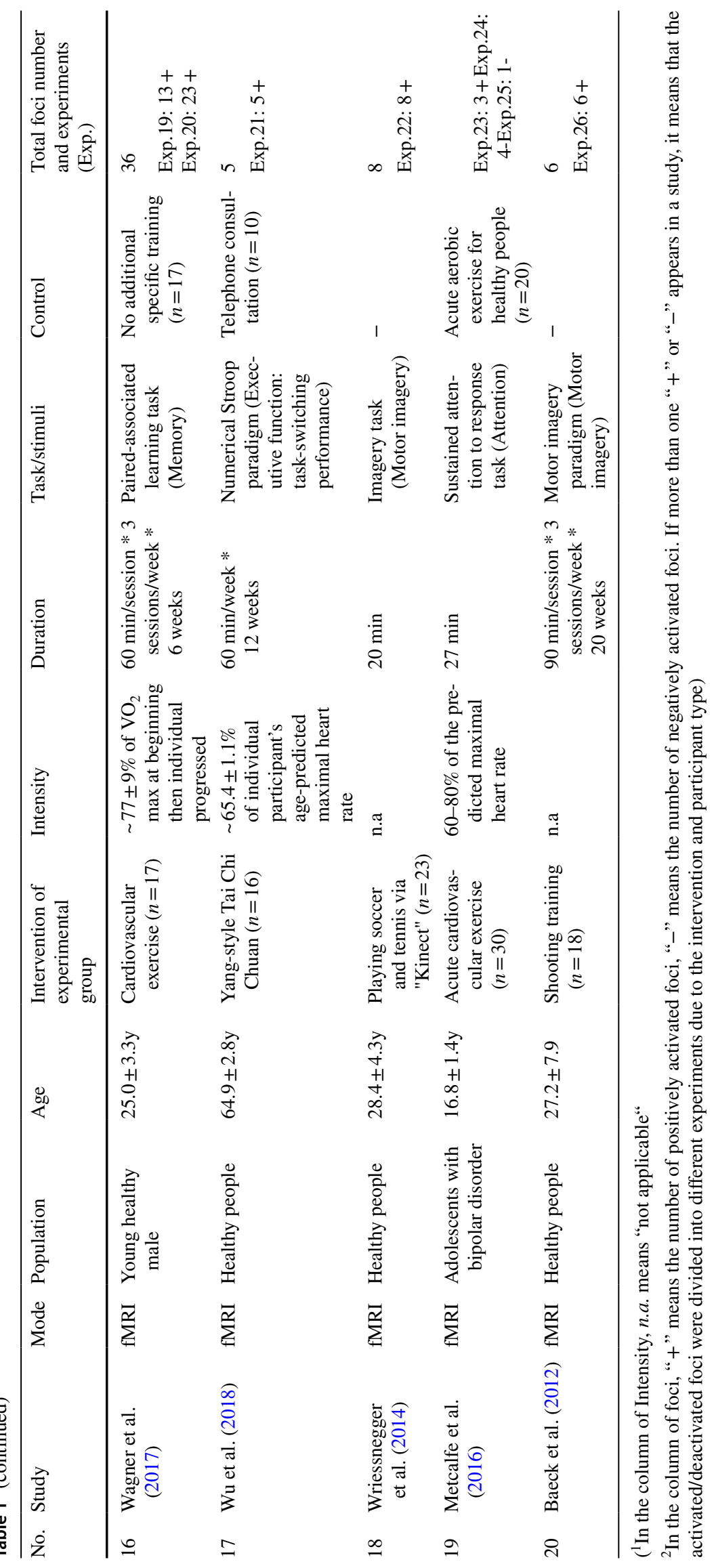




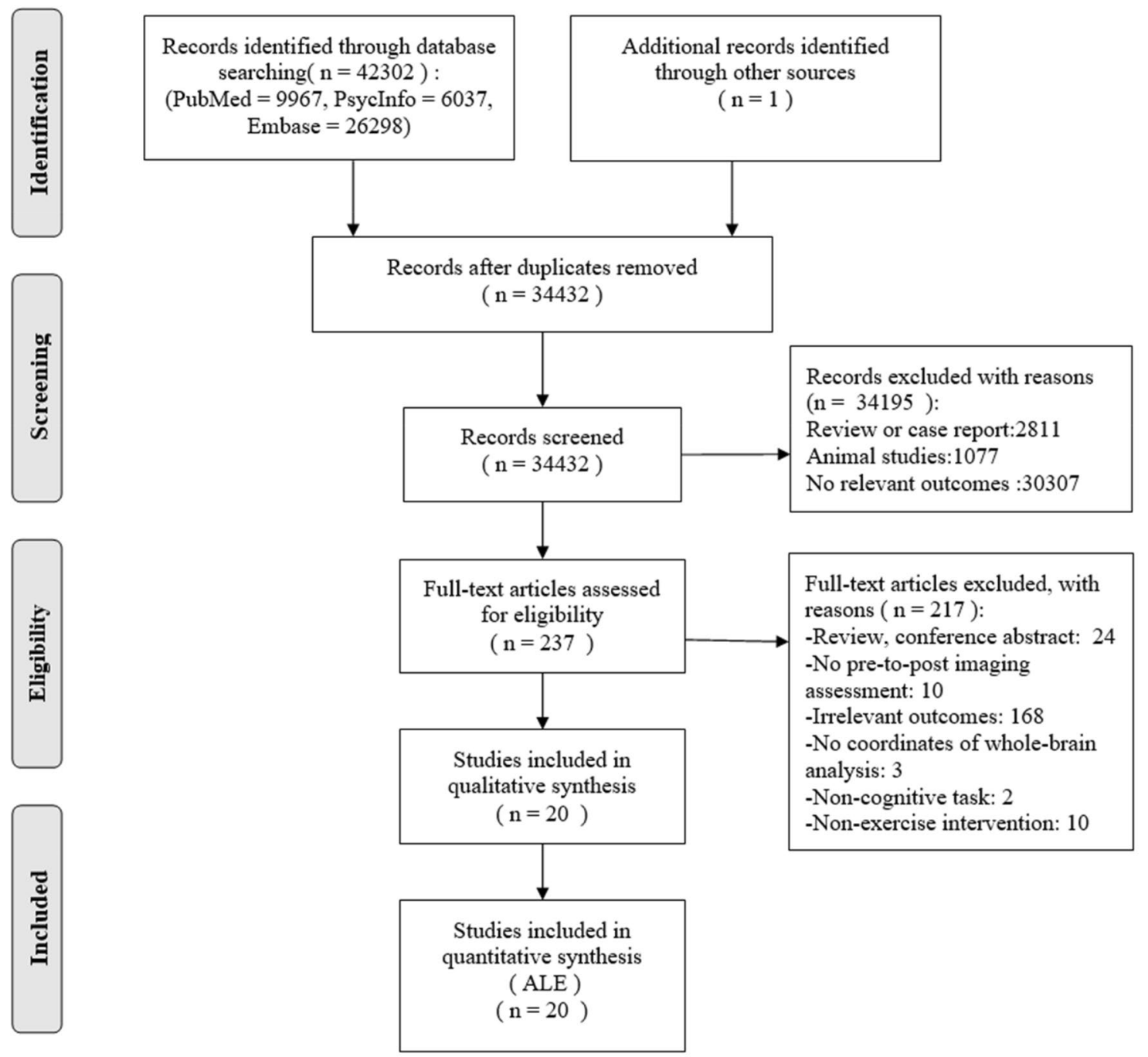

Fig. 1 Flowchart of literature searching, screening and assessment

included and converged on a $1616 \mathrm{~mm}^{3}$ cluster centered at $(38.1,-21.9,4.9)$ with 3 peaks (Fig. 2b) covering sub-lobar and temporal lobe regions in the right brain hemisphere. The cluster was primarily located in the lentiform nucleus (71.2\%) and spread in the adjacent claustrum (17.8\%), superior temporal gyrus $(6.8 \%)$, as well as the insula (4.1\%). Accordingly, the activated cluster comprises the Brodmann areas 13, 22 and 41 as well as the putamen. With respect to decreased activation reported in 9 experiments, no region of convergently decreased activation was identified.

\section{Subgroup analysis for health status}

For the healthy population (Baeck et al. 2012; Boa Sorte Silva et al. 2020; Chen et al. 2016; Krafft et al. 2014; Li et al. 2019; Liu-Ambrose et al. 2012; Nishiguchi et al. 2015; Pensel et al. 2018; Schmitt et al. 2019; Wagner et al. 2017; Wriessnegger et al. 2014; Wu et al. 2018), 168 foci from 14 experiments were included for the subgroup analysis; and for the patient population (Duchesne et al. 2016; Goldin et al. 2012a,b; Gourgouvelis et al. 2017; Hsu et al. 2018; Martinsen et al. 2018; Metcalfe et al. 2016; Smith et al. 2013), 92 foci from 12 experiments were selected. There was no activated cluster for either analysis.

\section{Subgroup analysis for age}

In the younger-age group (Baeck et al. 2012; Chen et al. 2016; Goldin et al. 2012a, b; Krafft et al. 2014; Li et al. 2019; Metcalfe et al. 2016; Schmitt et al. 2019; Wagner et al. 2017; Wriessnegger et al. 2014), 103 activation foci from 15 experiments were included and converged on $2112 \mathrm{~mm}^{3}$ cluster centered at $(14.1,-62.2,30.8)$ with 3 peaks (Fig. 2c) located at the occipital, parietal and limbic lobe. The identified cluster primarily encompassed the precuneus (78.5\%), spreading into the adjacent cuneus $(10.3 \%)$, posterior 


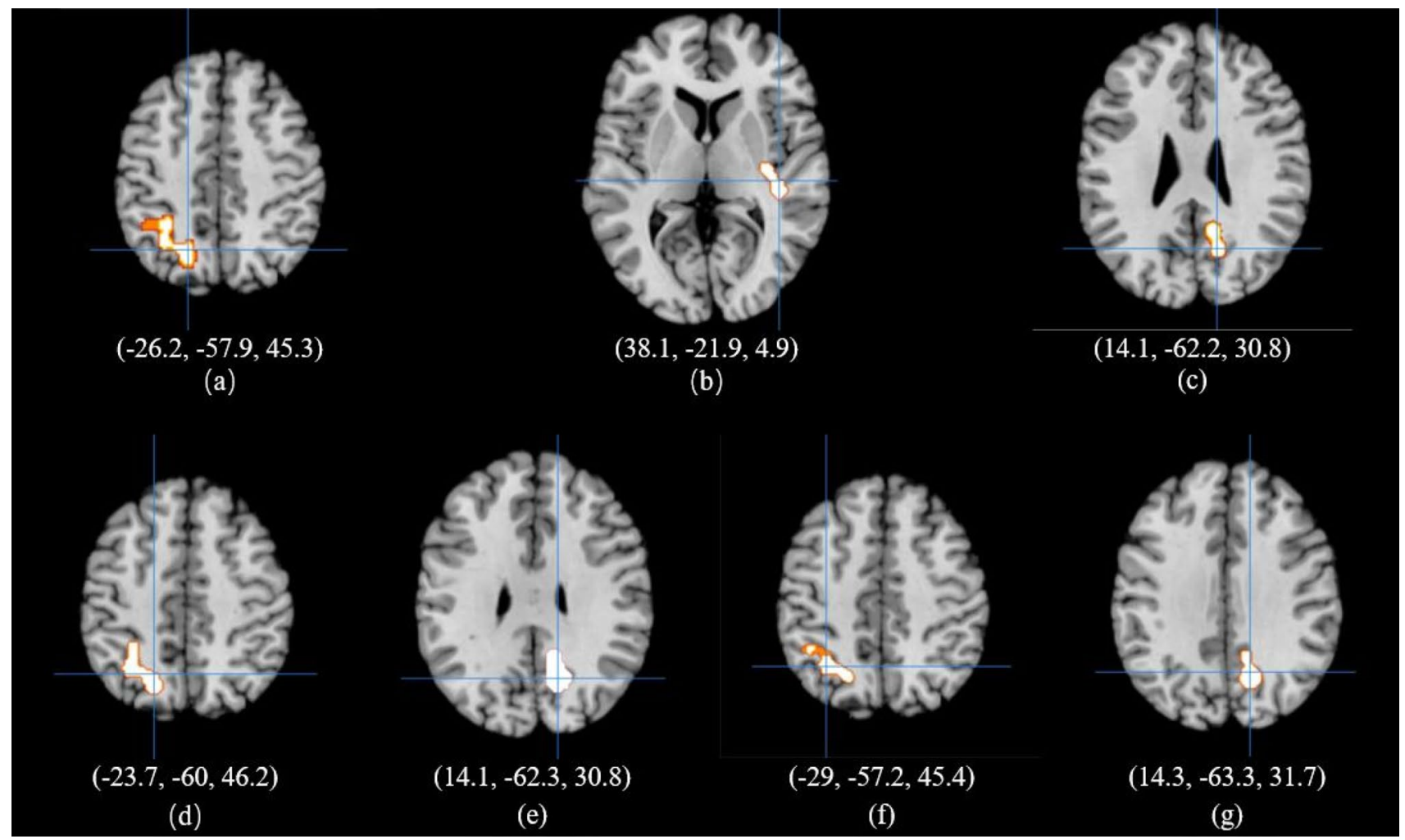

Fig. 2 Activated clusters in overall analysis and subgroup analyses. Notes: a activation for overall analysis; $\mathbf{b}$ increased activation; $\mathbf{c}$ activation for $<35$-year-old subgroup; $\mathbf{d}$ activation for $\geq 35$-year-old sub-

cingulate (6.5\%), and cingulate gyrus (4.7\%). The cluster encompassed regions located in Brodmann areas 7 and 31.

In the older-age group (Boa Sorte Silva et al. 2020; Duchesne et al. 2016; Gourgouvelis et al. 2017; Hsu et al. 2018; Liu-Ambrose et al. 2012; Martinsen et al. 2018; Nishiguchi et al. 2015; Pensel et al. 2018; Smith et al. 2013; Wu et al. 2018), 157 foci from 11 experiments were included and converged on a $2360-\mathrm{mm}^{3}$ cluster spanning from $(-36$, $-72,40)$ to $(-10,-44,56)$, with the center at $(-23.7,-60$, 46.2) (Fig. 2d). The 4 peaks of this cluster were located in the parietal lobe of the left hemisphere. The identified cluster was mainly located in the precuneus $(82.2 \%)$, and additionally encompassed the inferior parietal lobule (6.7\%), superior parietal lobule (6.7\%), and angular gyrus (4.4\%). In addition, the cluster included regions located in Brodmann areas 7,19 and 39 .

\section{Subgroup analysis for intervention duration}

For the shorter-term duration interventions (Chen et al. 2016; Goldin et al. 2012a,b; Gourgouvelis et al. 2017; Li et al. 2019; Liu-Ambrose et al. 2012; Metcalfe et al. 2016; Schmitt et al. 2019; Wagner et al. 2017; Wriessnegger et al. 2014), 109 foci from 14 experiments converged on a $2008-\mathrm{mm}^{3}$ cluster group; $\mathbf{e}$ activation for $<12$-week subgroup; $\mathbf{f}$ activation for $\geq 12$-week subgroup; $\mathbf{g}$ activation for physically inactive subgroup

centered at $(14.1,-62.3,30.8)$ with 3 peaks in right hemisphere (Fig. 2e). Among these peaks, 1 peak with the maximum value was located in the occipital lobe and 2 peaks were situated in the limbic lobe. The cluster was primarily located in the precuneus (80.2\%), spreading into the cuneus (10.9\%), posterior cingulate (5\%), and cingulate gyrus (4\%). At the brain region level, Brodmann areas 31 and 7 contributed to $73.3 \%$ and $25.7 \%$ to this cluster, respectively. For the longerterm duration interventions (Baeck et al. 2012; Boa Sorte Silva et al. 2020; Duchesne et al. 2016; Hsu et al. 2018; Krafft et al. 2014; Martinsen et al. 2018; Nishiguchi et al. 2015; Pensel et al. 2018; Smith et al. 2013; Wu et al. 2018), 151 foci from 12 experiments converged on a $1968-\mathrm{mm}^{3}$ cluster centered at $(-29,-57.2,45.4)$ with 4 peaks in the parietal lobe of left cerebrum (Fig. 2f). The cluster encompassed the precuneus (45.5\%), as well as the inferior parietal lobule (45.5\%), angular gyrus $(6.1 \%)$, and supramarginal gyrus (3\%) corresponding to Brodmann areas 7, 19, 39 and 40.

\section{Subgroup analysis for total amount of physical activity}

In the PIG (Chen et al. 2016; Duchesne et al. 2016; Gourgouvelis et al. 2017; Hsu et al. 2018; Krafft et al. 
2014; Liu-Ambrose et al. 2012; Martinsen et al. 2018; Metcalfe et al. 2016; Nishiguchi et al. 2015; Schmitt et al. 2019; Wriessnegger et al. 2014; Wu et al. 2018), 85 foci from 16 experiments converged on a $1792-\mathrm{mm}^{3}$ cluster centered at $(14.3,-63.3,31.7)$ with 2 peaks (Fig. 2g). Peaks 1 and 2 were located in the right occipital lobe and in the right limbic lobe, respectively. The cluster covered the occipital lobe, parietal lobe and limbic lobes. The cluster primarily included the precuneus (83.8\%), and cuneus $(33.3 \%)$ with additional engagement of the cingulate gyrus (5.1\%), which correspond to Brodmann area 31 (72.7\%) and Brodmann area 7 (27.3\%). In the PAG (Baeck et al. 2012; Boa Sorte Silva et al. 2020; Goldin et al. 2012a, b; Hsu et al. 2018; Pensel et al. 2018; Smith et al. 2013; Wagner et al. 2017), 175 foci from 10 experiments did not converge on a robust cluster.

\section{Anatomical connectivity, functional connectivity and functional characterizations of activated brain regions}

In this study, each activated cluster includes more than one peak with each one that can generate a sub-region (radius $=3 \mathrm{~mm}$ ). Anatomical and functional connectivity of activated sub-regions (4 peaks) in the overall analysis and subgroup analyses are shown in Fig. 3. Functional characterizations of activated sub-regions in both overall analysis and subgroup analyses are summarized in Tables 2, 3, and revealed that the identified sub-regions in the overall analysis exhibited a strong positive coupling with the entire frontoparietal control network and were functionally characterized by engagement in core cognitive domains, including attention, executive functions and working memory. For the functional characterizations, sub-regions were connected with spatial cognition in the overall analysis. In the subgroup analyses, activated sub-regions were associated with explicit memory in the younger-age group, shorter-term group, and PIG, whereas activated sub-regions were associated with working memory in the older-age group and longer-term intervention group. In addition, in both overall analysis and subgroup analysis (older-age group), activated sub-regions were associated with paradigms measuring mental rotation.

In the overall analysis, the frontoparietal and dorsal attention networks were involved in exercise-induced changes in functional activation patterns. For subgroup analyses, associated networks varied across subgroups: (1) younger-age group (frontoparietal network) and older-age group (dorsal attention network); (2) shorter-term group (frontoparietal and default networks) and longer-term group (frontoparietal and dorsal attention networks); (3) PIG (frontoparietal and default networks).

\section{Risk of bias assessment}

Total score across included studies ranged from 3 to 7 $(M=4.80$ and $\mathrm{SD}=1.40)$ that correspond to poor to good quality. Notably, only two studies scored 7 . Points in the majority of included studies were mainly deducted due to their study design such as lack of random allocation $(n=9)$, concealed allocation $(n=14)$, assessor blinding $(n=18)$, intention-to-treat analysis $(n=18)$. Detailed information is displayed in Supplementary data 2.

\section{Discussion}

\section{Exercise-induced brain activation associated with cognition}

The overall meta-analysis encompassing data from all original studies demonstrated robust exercise-induced changes in cognition-related functional activation of the left parietal lobe, primarily covering the precuneus $(69.7 \%)$ and spreading into inferior (27.3\%) and superior (3\%) parietal lobe. The precuneus plays a key role in a range of highly integrated mental processes, ranging from basic cognitive processes to regulatory control over performance under stress (Cavanna 2006; Zhao et al. 2020). The integrative function of the precuneus is further reflected in the functional connectivity profiles of these regions, which include separable interactions with networks engaged in sensorimotor and cognitive processes (e.g., executive function, episodic memory, visuospatial processing) (LJ 2006). Sporns and Bullmore proposed that the precuneus plays a key role in in the frontoparietal network by interconnecting parietal and prefrontal regions ("small-world network" hub), which provides an explanation for the aforementioned activation during cognitive tasks (Bullmore 2009). Moreover, the precuneus is a brain region which is commonly affected in individuals with mild cognitive impairment and early stages of Alzheimer's disease (Jacobs et al. 2012). In light of this observation, our findings suggest that regular physical exercise can be a valuable approach to prevent cognitive decline (Alty et al. 2020; Bherer et al. 2013; Kivipelto et al. 2018) by enhancing the functional integration of the frontoparietal control network via effects on the precuneus.

The activated sub-regions were connected with dorsal attention network and frontoparietal network, and the functional characterizations revealed a strong engagement in core cognitive domains, including attention as well as executive functions. The frontoparietal network is a functional hub sharing connectivity with diverse brain networks and plays an essential role in modulating cognitive control (Power et al. 2013). Moreover, the degree of frontoparietal network's coupling with other brain networks (especially 


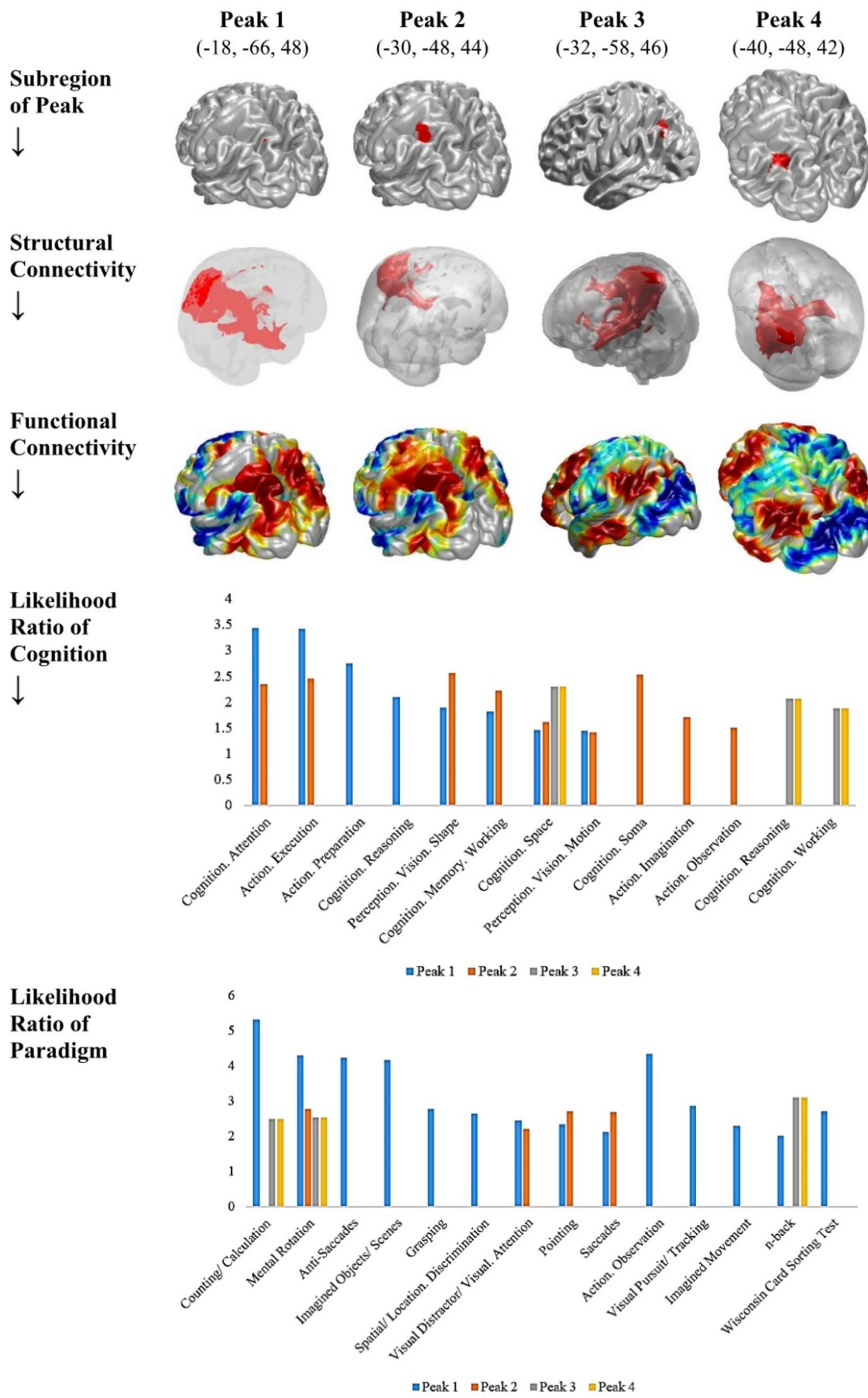

Fig. 3 Anatomical connectivity, functional connectivity and functional characterizations of activated brain sub-regions in the overall analysis 
Table 2 Characterizations of activated brain regions in overall analysis

\begin{tabular}{|c|c|c|c|c|c|c|c|c|}
\hline & \multicolumn{3}{|c|}{ Coordinate } & \multirow[t]{2}{*}{ Location } & \multirow{2}{*}{$\begin{array}{l}\text { Likelihood ratio of behavioral } \\
\text { domain }\end{array}$} & & \multirow[t]{2}{*}{ Likelihood ratio of paradigm } & \\
\hline & $x$ & $y$ & $z$ & & & & & \\
\hline \multirow[t]{9}{*}{ Peak 1} & \multirow[t]{9}{*}{-18} & \multirow[t]{9}{*}{-66} & \multirow[t]{9}{*}{48} & \multirow{9}{*}{$\begin{array}{l}\text { Left Cerebrum. Parietal Lobe. Precu- } \\
\text { neus. Gray Matter. Brodmann area } 7\end{array}$} & Cognition. Attention & 3.44 & Counting/calculation & 5.31 \\
\hline & & & & & Action. Execution & 3.41 & Mental Rotation@ & 4.28 \\
\hline & & & & & Action. Preparation & 2.75 & Anti-Saccades & 4.23 \\
\hline & & & & & Cognition. Reasoning & 2.10 & Imagined Objects/scenes & 4.15 \\
\hline & & & & & Perception. Vision. Shape & 1.90 & Grasping & 2.77 \\
\hline & & & & & Cognition. Memory. Working & 1.82 & Spatial/Location. Discrimination & 2.65 \\
\hline & & & & & Cognition. Space ${ }^{\circledR}$ & 1.46 & Visual Distractor/Visual. Attention & 2.45 \\
\hline & & & & & Perception. Vision. Motion & 1.45 & Pointing & 2.33 \\
\hline & & & & & & & Saccades & 2.11 \\
\hline \multirow[t]{9}{*}{ Peak 2} & \multirow[t]{9}{*}{-30} & \multirow[t]{9}{*}{-48} & \multirow[t]{9}{*}{44} & \multirow{9}{*}{$\begin{array}{l}\text { Left Cerebrum. Parietal Lobe. Supe- } \\
\text { rior Parietal Lobule. Gray Matter } \\
\text { Brodmann area } 7\end{array}$} & Perception. Vision. Shape & 2.56 & Action. Observation & 4.34 \\
\hline & & & & & Cognition. Soma & 2.53 & Visual Pursuit/Tracking & 2.85 \\
\hline & & & & & Action. Execution & 2.45 & Mental Rotation@ & 2.77 \\
\hline & & & & & Cognition. Attention & 2.35 & Pointing & 2.70 \\
\hline & & & & & Cognition. Memory. Working & 2.22 & Saccades & 2.69 \\
\hline & & & & & Action. Imagination & 1.71 & Imagined Movement & 2.29 \\
\hline & & & & & Cognition. Space ${ }^{\circledR}$ & 1.61 & Visual Distractor/Visual. Attention & 2.20 \\
\hline & & & & & Action. Observation & 1.51 & n-back & 2.01 \\
\hline & & & & & Perception. Vision. Motion & 1.41 & & \\
\hline \multirow[t]{4}{*}{ Peak 3} & \multirow[t]{4}{*}{-32} & \multirow[t]{4}{*}{-58} & \multirow[t]{4}{*}{46} & \multirow{4}{*}{$\begin{array}{l}\text { Left Cerebrum. Parietal Lobe. Inferior } \\
\text { Parietal Lobule. Gray Matter } \\
\text { Brodmann area } 39\end{array}$} & Cognition. Space ${ }^{\circledR}$ & 2.29 & n-back & 3.1 \\
\hline & & & & & Cognition. Reasoning & 2.06 & Wisconsin Card Sorting Test & 2.71 \\
\hline & & & & & Cognition. Working & 1.88 & Mental Rotation@ & 2.53 \\
\hline & & & & & & & Counting/Calculation & 2.49 \\
\hline \multirow[t]{4}{*}{ Peak 4} & \multirow[t]{4}{*}{-40} & \multirow[t]{4}{*}{-48} & \multirow[t]{4}{*}{42} & \multirow{4}{*}{$\begin{array}{l}\text { Left Cerebrum. Parietal Lobe. Inferior } \\
\text { Parietal Lobule. Gray Matter } \\
\text { Brodmann area } 40\end{array}$} & Cognition. Space ${ }^{\circledR}$ & 2.29 & n-back & 3.1 \\
\hline & & & & & Cognition. Reasoning & 2.06 & Wisconsin Card Sorting Test & 2.71 \\
\hline & & & & & Cognition. Working & 1.88 & Mental Rotation@ & 2.53 \\
\hline & & & & & & & Counting/Calculation & 2.49 \\
\hline
\end{tabular}

( and @ indicate overlapping behavioral domain(s) or paradigm(s) across sub-regions, respectively

default mode network) is positively correlated with fluid intelligence (e.g., problem solving/executive function and visuospatial ability) and overall cognitive ability (Cole et al. 2015; Sheffield et al. 2015), which is consistent with our results in overall analysis for global cognition (all cognitive components were pooled together for the overall analysis). The dorsal attention network, centered around the intraparietal sulcus and frontal eye fields, participates in top-down control of attention as well as sensory-motor information integration, which support several higher level cognitive domains (Fox et al. 2006).

\section{Moderators have impact on exercise-induced cognitive improvement}

In this review, age and training duration considerably moderated exercise effects on brain activation that is associated with anatomical and functional networks. For instance, in the younger-age group, the identified sub-regions are associated with explicit memory. This result is strongly supported by a recent meta-analysis (including 25 experimental studies) demonstrating robust effects of exercise on episodic memory function (Loprinzi et al. 2019). Furthermore, the recruited participants in 23 studies were reported with age range of 18 to 30 years old, which coincides with the younger-age group (less than 35 years old) in the current review. In the older-age group, identified sub-regions are related to executive functions, including working memory, spatial cognition and mental rotation. Such improvements induced by exercise have been well-documented in previous meta-analytical studies at the behavioral level (Chen et al. 2020b; Falck et al. 2019; Northey et al. 2018).

With regard to the moderating effect of training duration on exercise-induced activation, shorter-term exercise interventions induced primarily changes in occipital, parietal and limbic regions and the peaks/sub-regions are generally linked to explicit memory, whereas the longer-term training protocols induced changes in activation in the parietal lobe. Of note, the shorter-term group included 14 experiments with 7 using acute physical exercise, which is partially 
Table 3 Characterizations of activated brain regions in subgroup analyses

\begin{tabular}{|c|c|c|c|c|c|c|c|c|}
\hline & Coor & dinate & & Location & Likelihood ratio of behavioral & & Likelihood ratio of paradigm & \\
\hline & $x$ & $y$ & $z$ & & & & & \\
\hline$<35$ Yea & ars Old & Subg & roup & & & & & \\
\hline Peak 1 & 14 & -64 & 32 & $\begin{array}{l}\text { Right Cerebrum. Occipital Lobe. } \\
\text { Precuneus. Gray Matter. Brod- } \\
\text { mann area } 31\end{array}$ & $\begin{array}{l}\text { Perception. Vision. Motion } \\
\text { Cognition. Memory. Explicit® }\end{array}$ & $\begin{array}{l}2.06 \\
1.94\end{array}$ & Saccades & 2.51 \\
\hline Peak 2 & 12 & -52 & 32 & $\begin{array}{l}\text { Right Cerebrum. Limbic Lobe. } \\
\text { Cingulate Gyrus. Gray Matter. } \\
\text { Brodmann area } 31\end{array}$ & $\begin{array}{l}\text { Cognition. Social Cognition } \\
\text { Cognition. Memory. Explicit }{ }^{\circledR}\end{array}$ & $\begin{array}{l}3.11 \\
2.45\end{array}$ & $\begin{array}{l}\text { Cued Explicit. Recognition } \\
\text { Episodic Recall } \\
\text { Theory of Mind Task }\end{array}$ & $\begin{array}{l}5.88 \\
3.48 \\
2.46\end{array}$ \\
\hline Peak 3 & 12 & -54 & 22 & $\begin{array}{l}\text { Right Cerebrum. Limbic Lobe. } \\
\text { Posterior Cingulate. Gray Matter. } \\
\text { Brodmann area } 23\end{array}$ & $\begin{array}{l}\text { Perception. Vision. Motion } \\
\text { Cognition. Memory. Explicit }{ }^{\circledR}\end{array}$ & $\begin{array}{l}2.06 \\
1.94\end{array}$ & Saccades & 2.51 \\
\hline$\geq 35$ Yea & ars Old & Subg & roup & & & & & \\
\hline Peak 1 & -18 & -68 & 48 & $\begin{array}{l}\text { Left Cerebrum. Parietal Lobe. Pre- } \\
\text { cuneus. Gray Matter. Brodmann } \\
\text { area } 7\end{array}$ & $\begin{array}{l}\text { Cognition. Attention } \\
\text { Action. Execution } \\
\text { Action. Preparation } \\
\text { Cognition. Reasoning } \\
\text { Perception. Vision. Shape } \\
\text { Cognition. Memory. Working® } \\
\text { Cognition. Space }{ }^{\circledR} \\
\text { Perception. Vision. Motion }\end{array}$ & $\begin{array}{l}3.44 \\
3.41 \\
2.75 \\
2.10 \\
1.90 \\
1.82 \\
1.46 \\
1.45\end{array}$ & $\begin{array}{l}\text { Counting/Calculation } \\
\text { Mental Rotation } \\
\text { Anti-Saccades } \\
\text { Imagined Objects/Scenes } \\
\text { Grasping } \\
\text { Spatial/Location. Discrimination } \\
\text { Visual Distractor/Visual. Attention } \\
\text { Pointing } \\
\text { Saccades }\end{array}$ & $\begin{array}{l}5.31 \\
4.28 \\
4.23 \\
4.15 \\
2.77 \\
2.65 \\
2.45 \\
2.33 \\
2.11\end{array}$ \\
\hline Peak 2 & -30 & -48 & 44 & $\begin{array}{l}\text { Left Cerebrum. Parietal Lobe. } \\
\text { Superior Parietal Lobule. Gray } \\
\text { Matter. Brodmann area } 7\end{array}$ & $\begin{array}{l}\text { Perception. Vision. Shape } \\
\text { Cognition. Soma } \\
\text { Action. Execution } \\
\text { Cognition. Attention } \\
\text { Cognition. Memory. Working } ® \\
\text { Action. Imagination } \\
\text { Cognition. Space® } \\
\text { Action. Observation } \\
\text { Perception. Vision. Motion }\end{array}$ & $\begin{array}{l}2.56 \\
2.53 \\
2.45 \\
2.35 \\
2.22 \\
1.71 \\
1.61 \\
1.51 \\
1.41\end{array}$ & $\begin{array}{l}\text { Action. Observation } \\
\text { Visual Pursuit/Tracking } \\
\text { Mental Rotation } \\
\text { Pointing } \\
\text { Saccades } \\
\text { Imagined Movement } \\
\text { Visual Distractor/Visual. Attention } \\
\text { n-back }\end{array}$ & $\begin{array}{l}4.34 \\
2.85 \\
2.77 \\
2.70 \\
2.69 \\
2.29 \\
2.20 \\
2.01\end{array}$ \\
\hline Peak 3 & -32 & -58 & 46 & $\begin{array}{l}\text { Left Cerebrum. Parietal Lobe. Infe- } \\
\text { rior Parietal Lobule. Gray Matter. } \\
\text { Brodmann area } 39\end{array}$ & $\begin{array}{l}\text { Cognition. Space }{ }^{\circledR} \\
\text { Cognition. Reasoning } \\
\text { Cognition. Memory. Working® }\end{array}$ & $\begin{array}{l}2.29 \\
2.06 \\
1.88\end{array}$ & $\begin{array}{l}\text { n-back } \\
\text { Wisconsin Card Sorting Test } \\
\text { Mental Rotation } \\
\text { Counting/Calculation }\end{array}$ & $\begin{array}{l}3.10 \\
2.71 \\
2.53 \\
2.49\end{array}$ \\
\hline Peak 4 & -12 & -64 & 54 & $\begin{array}{l}\text { Left Cerebrum. Parietal Lobe. Pre- } \\
\text { cuneus. Gray Matter. Brodmann } \\
\text { area } 7\end{array}$ & - & - & - & - \\
\hline$<12$ wee & eks sub & ogroup & & & & & & \\
\hline Peak 1 & 14 & -64 & 32 & $\begin{array}{l}\text { Right Cerebrum. Occipital Lobe. } \\
\text { Precuneus. Gray Matter. Brod- } \\
\text { mann area } 31\end{array}$ & $\begin{array}{l}\text { Perception. Vision. Motion } \\
\text { Cognition. Memory. Explicit® }\end{array}$ & $\begin{array}{l}2.06 \\
1.94\end{array}$ & Saccades & 2.51 \\
\hline Peak 2 & 12 & -52 & 32 & $\begin{array}{l}\text { Right Cerebrum. Limbic Lobe. } \\
\text { Cingulate Gyrus. Gray Matter. } \\
\text { Brodmann area } 31\end{array}$ & $\begin{array}{l}\text { Cognition. Social Cognition } \\
\text { Cognition. Memory. Explicit }{ }^{\circledR}\end{array}$ & $\begin{array}{l}3.11 \\
2.45\end{array}$ & $\begin{array}{l}\text { Cued Explicit. Recognition } \\
\text { Episodic Recall } \\
\text { Theory of Mind Task }\end{array}$ & $\begin{array}{l}5.88 \\
3.48 \\
2.46\end{array}$ \\
\hline Peak 3 & 12 & -54 & 22 & $\begin{array}{l}\text { Right Cerebrum. Limbic Lobe. } \\
\text { Posterior Cingulate. Gray Matter. } \\
\text { Brodmann area } 23\end{array}$ & $\begin{array}{l}\text { Perception. Vision. Motion } \\
\text { Cognition. Memory. Explicit }{ }^{\circledR}\end{array}$ & $\begin{array}{l}2.06 \\
1.94\end{array}$ & Saccades & 2.51 \\
\hline
\end{tabular}

supported by results from a previous meta-analysis which investigated the beneficial effects of acute exercise on episodic memory as a type of explicit memory (Tulving 1972).
Meanwhile, researchers emphasized that the timing of acute exercise plays an important role in the interaction of exercise and memory; such that cognitive improvement was observed 
Table 3 (continued)

\begin{tabular}{|c|c|c|c|c|c|c|c|c|}
\hline & \multicolumn{3}{|c|}{ Coordinate } & \multirow[t]{2}{*}{ Location } & \multirow{2}{*}{$\begin{array}{l}\text { Likelihood ratio of behavioral } \\
\text { domain }\end{array}$} & & \multirow[t]{2}{*}{ Likelihood ratio of paradigm } & \\
\hline & $x$ & $y$ & $z$ & & & & & \\
\hline \multicolumn{9}{|c|}{$\geq 12$ weeks subgroup } \\
\hline \multirow[t]{4}{*}{ Peak 1} & \multirow[t]{4}{*}{-32} & \multirow[t]{4}{*}{-58} & \multirow[t]{4}{*}{46} & \multirow{4}{*}{$\begin{array}{l}\text { Left Cerebrum. Parietal Lobe. Infe- } \\
\text { rior Parietal Lobule. Gray Matter. } \\
\text { Brodmann area } 39\end{array}$} & Cognition. Space ${ }^{\circledR}$ & 2.29 & n-back & 3.10 \\
\hline & & & & & Cognition. Reasoning ${ }^{\circledR}$ & 2.06 & Wisconsin Card Sorting Test & 2.71 \\
\hline & & & & & Cognition. Memory. Working® & 1.88 & Mental Rotation & 2.53 \\
\hline & & & & & & & Counting/Calculation & 2.49 \\
\hline \multirow[t]{4}{*}{ Peak 2} & \multirow[t]{4}{*}{-40} & \multirow[t]{4}{*}{-48} & \multirow[t]{4}{*}{42} & \multirow{4}{*}{$\begin{array}{l}\text { Left Cerebrum. Parietal Lobe. Infe- } \\
\text { rior Parietal Lobule. Gray Matter. } \\
\text { Brodmann area } 40\end{array}$} & Cognition. Space ${ }^{\circledR}$ & 2.29 & n-back & 3.10 \\
\hline & & & & & Cognition. Reasoning ${ }^{\circledR}$ & 2.06 & Wisconsin Card Sorting Test & 2.71 \\
\hline & & & & & Cognition. Memory. Working® & 1.88 & Mental Rotation & 2.53 \\
\hline & & & & & & & Counting/calculation & 2.49 \\
\hline \multirow[t]{6}{*}{ Peak 3} & \multirow[t]{6}{*}{-20} & \multirow[t]{6}{*}{-64} & \multirow{6}{*}{46} & \multirow{6}{*}{$\begin{array}{l}\text { Left Cerebrum. Parietal Lobe. Pre- } \\
\text { cuneus. Gray Matter. Brodmann } \\
\text { area } 7\end{array}$} & Cognition. Reasoning ${ }^{\circledR}$ & 3.25 & Saccades & 3.54 \\
\hline & & & & & Cognition. Memory. Working® & 2.92 & Delayed Match To Sample & 3.37 \\
\hline & & & & & Cognition. Attention & 2.81 & Stroop Task & 2.73 \\
\hline & & & & & Perception. Vision. Motion & 2.37 & Mental Rotation & 2.68 \\
\hline & & & & & Cognition. Space® & 1.72 & Wisconsin Card Sorting Test & 2.45 \\
\hline & & & & & Perception. Vision. Shape & 1.68 & Task Switching & 2.44 \\
\hline Peak 4 & -12 & -64 & 54 & $\begin{array}{l}\text { Left Cerebrum. Parietal Lobe. Pre- } \\
\text { cuneus. Gray Matter. Brodmann } \\
\text { area } 7\end{array}$ & - & - & - & - \\
\hline \multicolumn{9}{|c|}{ Physically inactive subgroup } \\
\hline \multirow[t]{2}{*}{ Peak 1} & \multirow[t]{2}{*}{14} & \multirow[t]{2}{*}{-64} & \multirow[t]{2}{*}{32} & \multirow{2}{*}{$\begin{array}{l}\text { Right Cerebrum. Occipital Lobe. } \\
\text { Precuneus. Gray Matter. Brod- } \\
\text { mann area } 31\end{array}$} & Perception. Vision. Motion & 2.06 & \multirow[t]{2}{*}{ Saccades } & \multirow[t]{2}{*}{2.51} \\
\hline & & & & & Cognition. Memory. Explicit ${ }^{\circledR}$ & 1.94 & & \\
\hline \multirow[t]{3}{*}{ Peak 2} & \multirow[t]{3}{*}{12} & \multirow[t]{3}{*}{-52} & \multirow[t]{3}{*}{32} & \multirow{3}{*}{$\begin{array}{l}\text { Right Cerebrum. Limbic Lobe. } \\
\text { Cingulate Gyrus. Gray Matter. } \\
\text { Brodmann area } 31\end{array}$} & Cognition. Social Cognition & 3.11 & Cue Explicit. Recognition & 5.88 \\
\hline & & & & & Cognition. Memory. Explicit ${ }^{\circledR}$ & 2.45 & Episodic Recall & 3.48 \\
\hline & & & & & & & Theory of Mind Task & 2.46 \\
\hline
\end{tabular}

( ) and @ indicate overlapping behavioral domain(s) or paradigm(s) across sub-regions, respectively

with acute exercise occurring before memory encoding, during early memory consolidation and during late memory consolidation. Positive results on explicit memory function may be attributed to improved pattern separation (Suwabe et al. 2018; Voss et al. 2019) and attenuated memory interference (Crawford et al. 2020) following a relatively short intervention duration. For the longer-term group, the activated cluster was located in the parietal lobe and peak areas were associated with spatial processing, reasoning and working memory. For longer-term exercise, various positive effects on cognition have been reported at the molecular and cellular levels (e.g., brain-derived neurotrophic factor) (Hotting et al. 2016), structural level (e.g., increased gray matter volume in frontal and hippocampal regions) (Chaddock-Heyman et al. 2014), and behavioral level (e.g., improvement in executive function) (Fernandes et al. 2017; Kramer et al. 2005).

Of note, the analyses separately examining healthy subjects and patient groups did not converge on a specific brain region that exhibited changes. However, when lowering the statistical threshold (uncorrected) convergent activation in the parietal lobe emerged for both, healthy subjects and patients (detailed information can be found in supplementary data 3 ), indicating that the lack of convergent activation in the subgroups might be due to the reduced number of included experiments in each subgroup analysis. Besides, previous reviews have shown that both healthy people (Kramer and Colcombe 2018) and individuals with neurological, non-neurological, and psychiatric illnesses (Eggermont et al. 2006; Heyn et al. 2004) can benefit from physical exercise on the behavioral level. For instance, a meta-analysis by Dauwan et al., focusing on individuals with chronic disorders (Alzheimer's disease, Huntington's disease, multiple sclerosis, Parkinson's disease, schizophrenia, and unipolar depression), suggested that exercise interventions can improve several cognitive domains (attention, working memory and executive function) with small but significant effect sizes (Dauwan et al. 2016). In addition, an activated cluster was only observed in PIG, but not in PAG. Such results might be explained by physiological and psychological (cognitive) adaptation, which refers to that cellular stress and the resultant metabolic signals have reached relatively stable status (MacInnis and Gibala 2017). It is well known that fMRI measures brain activation by detecting 
blood-oxygen-level dependent response to cognitive tasks. Regarding the total amount of exercise, if cognitive benefits reach a peak at 150-min exercise or below, activation may no longer last as the amount of exercise increases due to blood-oxygen metabolism and neural adaptation (Logothetis et al. 2001).

In addition, currently there is no sufficient number of studies available, which would allow to investigate how other important moderators, namely type of exercise and exercise intensity, can influence functional brain activation patterns. In this context, behavioral data suggest that coordinative exercise leads to greater benefits than purely aerobic exercises (Chen et al. 2020a; Ludyga et al. 2020). Hence, it seems a promising area for further research do investigate the underlying neural processes (e.g., functional brain activation patterns) driving this difference in behavioral findings. With regard to exercise intensity, the evidence from behavioral data is not univocal. In physical training studies no clear effect of exercise intensity could be observed (Ludyga et al. 2020), whereas in acute exercise studies the moderating effect of exercise intensity was clearly demonstrated as an exercising at higher intensity improves cognitive performance to a greater extent (Chang et al. 2012; Oberste et al. 2019). Hence, further studies are necessary to investigate whether the difference in behavioral findings, caused by the moderators type of exercise and exercise intensity, are mirrored in altered cognition-related functional brain activation patterns.

\section{Implications}

This is the first study to systematically examine the relationship between functional brain activation and cognition as a function of exercise practice. Therefore, the present results can be used to guide future research on exercise effects on brain health and cognition. Firstly, in the subgroup analyses of age and training duration, activation was observed in different brain regions. Follow-up studies should explore the associations between hemispheric lateralization and moderators (age and duration). Secondly, only the improvement of spatial cognition was observed in the overall analysis without consideration of moderators, while the benefits on various cognitive components like explicit memory, working memory and reasoning were found in the subgroup analyses. It can be inferred that the cognitive benefits from participating in physical exercise interventions are specifically influenced by age and training duration, which is consistent with previous behavioral meta-analytical reviews (Verburgh et al. 2014; Xue et al. 2019). Thirdly, because of the limited number of studies available for analysis, we cannot determine the influences of sex, exercise type, exercise intensity, and disease type on cognitive improvement. Given the high heterogeneity in the approaches to describe and report exercise intensity in the reviewed studies, a more standardized prescription of exercise intensity would be highly desirable to facilitate a meta-analytical data analysis and to simplify the reproducibility of the studies (Gronwald et al. 2019; Herold et al. 2020), although the optimal approach to describe exercise intensity is still debated (Herold et al. 2019, 2020; Herold 2020; Jamnick et al. 2020). However, these moderators should be examined in future well-designed exercise-cognition studies using neuroimaging techniques. Fourthly, the small number of included experiments has limited researchers to focus on two age groups only for subgroup analysis. Furthermore, original imaging studies on this topic that focused on children and adolescent, middle-aged people, young-old (55-65 years old) group, oldest-old population are still in its infancy, which requires further investigation. Fifth, results in this current meta-analysis are generated from pre-to-post experiment, instead of between-group contrast. As a result, observed positive changes could be attributed to a variety of other factors that interact with the physical exercise interventions. For example, when people start an physical exercise program, they may change their diet and/or have more social interaction that are highly associated with improved cognitive function (Bailey et al. 2019; Hardman et al. 2020; Yu et al. 2020). Thus, future imaging studies should include active and/or passive control group (s) in order to draw a firm conclusion about the cognitive benefits of physical exercise intervention (Herold et al. 2020). Lastly, when using the well-recognized PEDro scale for risk of bias assessment, the majority of included studies scored 7 below (blinding of participants and instructor are relatively difficult in physical exercise intervention, leading to 9 points in total). Moreover, the most of the reviewed has a relatively small sample size which can result in a low power influencing effect size estimation and reproducibility negatively (Button et al. 2013). Thus, more well-designed randomized controlled trials with an adequate sample size should be conducted on this topic to enhance the robustness of the findings.

\section{Conclusions}

The evidence for exercise effects on cognition is extensive but still growing. Combined with structural brain effects and behavioral data from previous studies, this article demonstrates that exercise-induced changes in functional brain activation in parietal regions (precuneus, superior and inferior parietal lobule, cingulate gyrus and posterior cingulate) and associated networks (frontoparietal network, dorsal attention network and default mode network) may neutrally mediate exercise-induced cognition enhancement. Furthermore, the present findings emphasize that the brain functional effects of exercise vary as a function of age and duration. 
Supplementary Information The online version contains supplementary material available at https://doi.org/10.1007/s00429-021-02247-2.

Acknowledgements Q.Y. and L.Y.Z. planned the meta-analysis and formulated the hypotheses. Q.Y. and L.Y.Z performed the literature search and screening. Q.YS., L.Y.Z and Y.J.Z conducted the data extraction and coding, calculated the effect sizes and rated the quality. Q.Y., B.K.B. and L.Y.Z performed the statistical analyses. Q.Y. F.H., and L.Y.Z drafted the initial version of the manuscript. All authors were involved in revisions of the draft.

Funding This research did not receive any specific grant from funding agencies in the public, commercial, or not-for-profit sectors.

Availability of data Online sources including Pubmed, Web of Science, PsycINFO, and Embase have been used for the purpose of the review.

\section{Compliance with ethical standards}

Declaration of interest The authors declare that they have no conflict of interest.

Research involving human participants and/or animals and informed consent This manuscript does not report on any findings from studies that enrolled human participants or animals. Rather, it synthesizes information gathered from existing literature and the informed consent is not applicable.

\section{References}

Allen C (2017) On (not) defining cognition. Synthese 194(11):42334249. https://doi.org/10.1007/s11229-017-1454-4

Alty J, Farrow M, Lawler K (2020) Exercise and dementia prevention. Pract Neurol 20(3):234-240. https://doi.org/10.1136/practneuro 1-2019-002335

Baeck JS, Kim YT, Seo JH et al (2012) Brain activation patterns of motor imagery reflect plastic changes associated with intensive shooting training. Behav Brain Res 234(1):26-32. https://doi. org/10.1016/j.bbr.2012.06.001

Bailey T, Shahabi L, Tarvainen M et al (2019) Moderating effects of the valence of social interaction on the dysfunctional consequences of perseverative cognition: an ecological study in major depression and social anxiety disorder. Anxiety Stress Coping 32(2):179-195. https://doi.org/10.1080/10615806.2019.1570821

Bayne T, Brainard D, Byrne RW et al (2019) What is cognition? Curr Biol 29(13):R608-r615. https://doi.org/10.1016/j. cub.2019.05.044

Bherer L, Erickson KI, Liu-Ambrose T (2013) A review of the effects of physical activity and exercise on cognitive and brain functions in older adults. J Aging Res 2013:657508. https://doi. org/10.1155/2013/657508

Boa Sorte Silva NC, Nagamatsu LS, Gill DP et al (2020) Memory function and brain functional connectivity adaptations following multiple-modality exercise and mind-motor training in older adults at risk of dementia: an exploratory sub-study. Front Aging Neurosci 12:22. https://doi.org/10.3389/fnagi.2020.00022

Boraxbekk CJ, Lundquist A, Nordin A et al (2015) Free recall episodic memory performance predicts dementia ten years prior to clinical diagnosis: findings from the betula longitudinal study. Dement Geriatr Cogn Dis Extra 5(2):191-202. https://doi. org/10.1159/000381535
Bostrom N, Sandberg A (2009) Cognitive enhancement: methods, ethics, regulatory challenges. Sci Eng Ethics 15(3):311-341. https ://doi.org/10.1007/s11948-009-9142-5

Bullmore E, Sporns O (2009) Complex brain networks: graph theoretical analysis of structural and functional systems. Nat Rev Neurosci 10(3):186-198. https://doi.org/10.1038/nrn2575

Button KS, Ioannidis JP, Mokrysz C et al (2013) Power failure: why small sample size undermines the reliability of neuroscience. Nat Rev Neurosci 14(5):365-376. https://doi.org/10.1038/nrn3475

Cavanna AE, Trimble MR (2006) The precuneus: a review of its functional anatomy and behavioural correlates. Brain 129(Pt 3):564583. https://doi.org/10.1093/brain/awl004

Chaddock-Heyman L, Erickson KI, Holtrop JL et al (2014) Aerobic fitness is associated with greater white matter integrity in children. Front Hum Neurosci 8:584. https://doi.org/10.3389/fnhum .2014 .00584

Chang YK, Labban JD, Gapin JI et al (2012) The effects of acute exercise on cognitive performance: a meta-analysis. Brain Res 1453:87-101. https://doi.org/10.1016/j.brainres.2012.02.068

Chen AG, Zhu LN, Yan J et al (2016) Neural basis of working memory enhancement after acute aerobic exercise: Fmri study of preadolescent children. Front Psychol 7:1804. https://doi.org/10.3389/ fpsyg.2016.01804

Chen FT, Etnier JL, Chan KH et al (2020a) Effects of exercise training interventions on executive function in older adults: a systematic review and meta-analysis. Sports Med 50(8):1451-1467. https ://doi.org/10.1007/s40279-020-01292-x

Chen FT, Etnier JL, Chan KH et al (2020b) Effects of exercise training interventions on executive function in older adults: a systematic review and meta-analysis. Sports Med. https://doi.org/10.1007/ s40279-020-01292-x

Chen FT, Hopman RJ, Huang CJ et al (2020c) The effect of exercise training on brain structure and function in older adults: a systematic review based on evidence from randomized control trials. J Clin Med. https://doi.org/10.3390/jcm9040914

Coelho FG, Gobbi S, Andreatto CA et al (2013) Physical exercise modulates peripheral levels of brain-derived neurotrophic factor (bdnf): a systematic review of experimental studies in the elderly. Arch Gerontol Geriatr 56(1):10-15. https://doi.org/10.1016/j. archger.2012.06.003

Cohen JA, Verghese J, Zwerling JL (2016) Cognition and gait in older people. Maturitas 93:73-77. https://doi.org/10.1016/j.matur itas.2016.05.005

Cole MW, Ito T, Braver TS (2015) Lateral prefrontal cortex contributes to fluid intelligence through multinetwork connectivity. Brain Connect 5(8):497-504. https://doi.org/10.1089/brain.2015.0357

Crawford LK, Li H, Zou L et al (2020) Hypothesized mechanisms through which exercise may attenuate memory interference. Medicina (Kaunas). https://doi.org/10.3390/medicina56030129

Dauwan M, Begemann MJ, Heringa SM et al (2016) Exercise improves clinical symptoms, quality of life, global functioning, and depression in schizophrenia: a systematic review and meta-analysis. Schizophr Bull 42(3):588-599. https://doi.org/10.1093/schbul/ sbv164

de Assis GG, de Almondes KM (2017) Exercise-dependent bdnf as a modulatory factor for the executive processing of individuals in course of cognitive decline. Syst Rev Front Psychol 8:584. https ://doi.org/10.3389/fpsyg.2017.00584

de Morton NA (2009) The pedro scale is a valid measure of the methodological quality of clinical trials: a demographic study. Aust J Physiother 55(2):129-133. https://doi.org/10.1016/s0004 -9514(09)70043-1

Dinoff A, Herrmann N, Swardfager W et al (2017) The effect of acute exercise on blood concentrations of brain-derived neurotrophic factor in healthy adults: a meta-analysis. Eur J Neurosci 46(1):1635-1646. https://doi.org/10.1111/ejn.13603 
Duchesne C, Gheysen F, Bore A et al (2016) Influence of aerobic exercise training on the neural correlates of motor learning in Parkinson's disease individuals. Neuroimage Clin 12:559-569. https://doi.org/10.1016/j.nicl.2016.09.011

Eggermont L, Swaab D, Luiten P et al (2006) Exercise, cognition and Alzheimer's disease: more is not necessarily better. Neurosci Biobehav Rev 30(4):562-575. https://doi.org/10.1016/j.neubi orev.2005.10.004

Eickhoff SB, Laird AR, Grefkes C et al (2009) Coordinate-based activation likelihood estimation meta-analysis of neuroimaging data: a random-effects approach based on empirical estimates of spatial uncertainty. Hum Brain Mapp 30(9):2907-2926. https://doi. org/10.1002/hbm.20718

Eickhoff SB, Nichols TE, Laird AR et al (2016) Behavior, sensitivity, and power of activation likelihood estimation characterized by massive empirical simulation. Neuroimage 137:70-85. https:// doi.org/10.1016/j.neuroimage.2016.04.072

Falck RS, Davis JC, Best JR et al (2019) Impact of exercise training on physical and cognitive function among older adults: a systematic review and meta-analysis. Neurobiol Aging 79:119-130. https:// doi.org/10.1016/j.neurobiolaging.2019.03.007

Fan L, Li H, Zhuo J et al (2016) The human brainnetome atlas: a new brain atlas based on connectional architecture. Cereb Cortex 26(8):3508-3526. https://doi.org/10.1093/cercor/bhw157

Fernandes J, Arida RM, Gomez-Pinilla F (2017) Physical exercise as an epigenetic modulator of brain plasticity and cognition. Neurosci Biobehav Rev 80:443-456. https://doi.org/10.1016/j.neubi orev.2017.06.012

Fox MD, Corbetta M, Snyder AZ et al (2006) Spontaneous neuronal activity distinguishes human dorsal and ventral attention systems. Proc Natl Acad Sci U S A 103(26):10046-10051. https://doi. org/10.1073/pnas.0604187103

Goldin P, Ziv M, Jazaieri H et al (2012a) Randomized controlled trial of mindfulness-based stress reduction versus aerobic exercise: effects on the self-referential brain network in social anxiety disorder. Front Hum Neurosci 6:295. https://doi.org/10.3389/fnhum .2012 .00295

Goldin P, Ziv M, Jazaieri H et al (2012b) Mbsr vs aerobic exercise in social anxiety: Fmri of emotion regulation of negative selfbeliefs. Soc Cogn Affect Neurosci 8(1):65-72. https://doi. org $/ 10.1093 / \mathrm{scan} / \mathrm{nss} 054$

Gourgouvelis J, Yielder P, Murphy B (2017) Exercise promotes neuroplasticity in both healthy and depressed brains: an fmri pilot study. Neural Plast 2017:8305287. https://doi. org/10.1155/2017/8305287

Gronwald T, de Alves BAC, Murillo-Rodriguez E et al (2019) Standardization of exercise intensity and consideration of a doseresponse is essential. Commentary on "exercise-linked fndc5/ irisin rescues synaptic plasticity and memory defects in alzheimer's models", by lourenco et al published 2019 in nature medicine. J Sport Health Sci. 8(4):353-354. https://doi.org/10.1016/j. jshs.2019.03.006

Harada CN, Natelson Love MC, Triebel KL (2013) Normal cognitive aging. Clin Geriatr Med 29(4):737-752. https://doi. org/10.1016/j.cger.2013.07.002

Hardman RJ, Meyer D, Kennedy G et al (2020) Findings of a pilot study investigating the effects of mediterranean diet and aerobic exercise on cognition in cognitively healthy older people living independently within aged-care facilities: the lifestyle intervention in independent living aged care (liilac) study. Curr Dev Nutr. 4(5):077. https://doi.org/10.1093/cdn/nzaa077

Harris JD, Quatman CE, Manring MM et al (2014) How to write a systematic review. Am J Sports Med 42(11):2761-2768. https:// doi.org/10.1177/0363546513497567

Hartshorne JK, Germine LT (2015) When does cognitive functioning peak? The asynchronous rise and fall of different cognitive abilities across the life span. Psychol Sci 26(4):433-443. https ://doi.org/10.1177/0956797614567339

Hedden T, Gabrieli JD (2004) Insights into the ageing mind: a view from cognitive neuroscience. Nat Rev Neurosci 5(2):87-96. https://doi.org/10.1038/nrn1323

Herold F, Aye N, Lehmann N et al (2020a) The contribution of functional magnetic resonance imaging to the understanding of the effects of acute physical exercise on cognition. Brain Sci. https ://doi.org/10.3390/brainsci10030175

Herold F, Gronwald T, Scholkmann F et al (2020b) New directions in exercise prescription: is there a role for brain- derived parameters obtained by functional near-infrared spectroscopy? Brain Sci. https://doi.org/10.3390/brainsci10060342

Herold F, Hamacher D, Schega L et al (2018) Thinking while moving or moving while thinking-concepts of motor-cognitive training for cognitive performance enhancement. Front Aging Neurosci 10:228. https://doi.org/10.3389/fnagi.2018.00228

Herold F, Muller P, Gronwald T et al (2019a) Dose-response matters!-a perspective on the exercise prescription in exercise-cognition research. Front Psychol 10:2338. https://doi. org/10.3389/fpsyg.2019.02338

Herold F, Torpel A, Hamacher D et al (2020c) A discussion on different approaches for prescribing physical interventions-four roads lead to rome, but which one should we choose? J Pers Med. https://doi.org/10.3390/jpm10030055

Herold F, Torpel A, Schega L et al (2019b) Functional and/or structural brain changes in response to resistance exercises and resistance training lead to cognitive improvements-a systematic review. Eur Rev Aging Phys Act 16:10. https://doi. org/10.1186/s11556-019-0217-2

Heyn P, Abreu BC, Ottenbacher KJ (2004) The effects of exercise training on elderly persons with cognitive impairment and dementia: a meta-analysis. Arch Phys Med Rehabil 85(10):1694-1704. https://doi.org/10.1016/j.apmr.2004.03.019

Hillman CH, Erickson KI, Kramer AF (2008) Be smart, exercise your heart: exercise effects on brain and cognition. Nat Rev Neurosci 9(1):58-65. https://doi.org/10.1038/nrn2298

Hotting K, Schickert N, Kaiser J et al (2016) The effects of acute physical exercise on memory, peripheral bdnf, and cortisol in young adults. Neural Plast 2016:6860573. https://doi. org/10.1155/2016/6860573

Hsu CL, Best JR, Davis JC et al (2018) Aerobic exercise promotes executive functions and impacts functional neural activity among older adults with vascular cognitive impairment. Br J Sports Med 52(3):184-191. https://doi.org/10.1136/bjsports2016-096846

Jacobs HI, Van Boxtel MP, Jolles J et al (2012) Parietal cortex matters in alzheimer's disease: an overview of structural, functional and metabolic findings. Neurosci Biobehav Rev 36(1):297-309. https ://doi.org/10.1016/j.neubiorev.2011.06.009

Jamnick NA, Pettitt RW, Granata C et al (2020) An examination and critique of current methods to determine exercise intensity. Sports Med 50(10):1729-1756. https://doi.org/10.1007/s4027 9-020-01322-8

Kelley GA, Kelley KS (2017) Exercise and sleep: a systematic review of previous meta-analyses. J Evid Based Med 10(1):26-36. https ://doi.org/10.1111/jebm.12236

Kivipelto M, Mangialasche F, Ngandu T (2018) Lifestyle interventions to prevent cognitive impairment, dementia and Alzheimer disease. Nat Rev Neurol 14(11):653-666. https://doi.org/10.1038/ s41582-018-0070-3

Knaepen K, Goekint M, Heyman EM et al (2010) Neuroplasticity-exercise-induced response of peripheral brain-derived neurotrophic factor: a systematic review of experimental studies in human subjects. Sports Med 40(9):765-801. https://doi. org/10.2165/11534530-000000000-00000 
Kovacevic A, Mavros Y, Heisz JJ et al (2018) The effect of resistance exercise on sleep: a systematic review of randomized controlled trials. Sleep Med Rev 39:52-68. https://doi.org/10.1016/j. smrv.2017.07.002

Krafft CE, Schwarz NF, Chi L et al (2014) An 8-month randomized controlled exercise trial alters brain activation during cognitive tasks in overweight children. Obesity (Silver Spring) 22(1):232242. https://doi.org/10.1002/oby.20518

Kramer AF, Colcombe S (2018) Fitness effects on the cognitive function of older adults: a meta- analytic study-revisited. Perspect Psychol Sci 13(2):213-217. https://doi.org/10.1177/1745691617 707316

Kramer AF, Colcombe SJ, McAuley E et al (2005) Fitness, aging and neurocognitive function. Neurobiol Aging 26(Suppl 1):124-127. https://doi.org/10.1016/j.neurobiolaging.2005.09.009

Laird AR, Robinson JL, McMillan KM et al (2010) Comparison of the disparity between talairach and mni coordinates in functional neuroimaging data: validation of the Lancaster transform. Neuroimage 51(2):677-683. https://doi.org/10.1016/j.neuroimage .2010 .02 .048

Li L, Zhang S, Cui J et al (2019) Fitness-dependent effect of acute aerobic exercise on executive function. Front Physiol 10:902. https://doi.org/10.3389/fphys.2019.00902

Liu-Ambrose T, Barha CK, Best JR (2018) Physical activity for brain health in older adults. Appl Physiol Nutr Metab 43(11):11051112. https://doi.org/10.1139/apnm-2018-0260

Liu-Ambrose T, Nagamatsu LS, Voss MW et al (2012) Resistance training and functional plasticity of the aging brain: a 12-month randomized controlled trial. Neurobiol Aging 33(8):1690-1698. https://doi.org/10.1016/j.neurobiolaging.2011.05.010

Liu H, Qin W, Li W et al (2013) Connectivity-based parcellation of the human frontal pole with diffusion tensor imaging. J Neurosci 33(16):6782-6790. https://doi.org/10.1523/jneur osci.4882-12.2013

Lj G (2006) Brodmann's localisation in the cerebral cortex. Springer, New York

Logothetis NK, Pauls J, Augath M et al (2001) Neurophysiological investigation of the basis of the fmri signal. Nature 412(6843):150-157. https://doi.org/10.1038/35084005

Loprinzi PD, Blough J, Crawford L et al (2019) The temporal effects of acute exercise on episodic memory function: systematic review with meta-analysis. Brain Sci. 9(4):87

Ludyga S, Gerber M, Brand S et al (2016) Acute effects of moderate aerobic exercise on specific aspects of executive function in different age and fitness groups: a meta-analysis. Psychophysiology 53(11):1611-1626. https://doi.org/10.1111/psyp.12736

Ludyga S, Gerber M, Puhse U et al (2020) Systematic review and meta-analysis investigating moderators of long-term effects of exercise on cognition in healthy individuals. Nat Hum Behav 4(6):603-612. https://doi.org/10.1038/s41562-020-0851-8

MacInnis MJ, Gibala MJ (2017) Physiological adaptations to interval training and the role of exercise intensity. J Physiol 595(9):29152930. https://doi.org/10.1113/jp273196

MacNeill SE, Lichtenberg PA (1997) Home alone: the role of cognition in return to independent living. Arch Phys Med Rehabil 78(7):755-758. https://doi.org/10.1016/s0003-9993(97)90085-x

Martinsen S, Flodin P, Berrebi J et al (2018) The role of long-term physical exercise on performance and brain activation during the stroop colour word task in fibromyalgia patients. Clin Physiol Funct Imaging 38(3):508-516. https://doi.org/10.1111/cpf.12449

Metcalfe AW, MacIntosh BJ, Scavone A et al (2016) Effects of acute aerobic exercise on neural correlates of attention and inhibition in adolescents with bipolar disorder. Transl Psychiatry 6:e814. https://doi.org/10.1038/tp.2016.85

Moher D, Liberati A, Tetzlaff J et al (2009) Preferred reporting items for systematic reviews and meta-analyses: the prisma statement.
PLoS Med 6(7):e1000097. https://doi.org/10.1371/journ al.pmed.1000097

Montero-Odasso M, Verghese J, Beauchet O et al (2012) Gait and cognition: a complementary approach to understanding brain function and the risk of falling. J Am Geriatr Soc 60(11):2127-2136. https://doi.org/10.1111/j.1532-5415.2012.04209.x

Morris R, Lord S, Bunce J et al (2016) Gait and cognition: mapping the global and discrete relationships in ageing and neurodegenerative disease. Neurosci Biobehav Rev 64:326-345. https://doi. org/10.1016/j.neubiorev.2016.02.012

Nishiguchi S, Yamada M, Tanigawa T et al (2015) A 12-week physical and cognitive exercise program can improve cognitive function and neural efficiency in community-dwelling older adults: a randomized controlled trial. J Am Geriatr Soc 63(7):1355-1363. https ://doi.org/10.1111/jgs.13481

Northey JM, Cherbuin N, Pumpa KL et al (2018) Exercise interventions for cognitive function in adults older than 50: a systematic review with meta-analysis. Br J Sports Med 52(3):154-160. https ://doi.org/10.1136/bjsports-2016-096587

Oberste M, Javelle F, Sharma S et al (2019) Effects and moderators of acute aerobic exercise on subsequent interference control: a systematic review and meta-analysis. Front Psychol 10:2616. https ://doi.org/10.3389/fpsyg.2019.02616

Park DC, Lautenschlager G, Hedden T et al (2002) Models of visuospatial and verbal memory across the adult life span. Psychol Aging 17(2):299-320

Park DC, Reuter-Lorenz P (2009) The adaptive brain: aging and neurocognitive scaffolding. Annu Rev Psychol 60:173-196. https:// doi.org/10.1146/annurev.psych.59.103006.093656

Pensel MC, Daamen M, Scheef L et al (2018) Executive control processes are associated with individual fitness outcomes following regular exercise training: blood lactate profile curves and neuroimaging findings. Sci Rep 8(1):4893. https://doi.org/10.1038/ s41598-018-23308-3

Piercy KL, Troiano RP, Ballard RM et al (2018) The physical activity guidelines for americans. JAMA 320(19):2020-2028. https://doi. org/10.1001/jama.2018.14854

Pontifex MB, McGowan AL, Chandler MC et al (2019) A primer on investigating the after effects of acute bouts of physical activity on cognition. Psychol Sport Exercise. 40:1-22. https://doi. org/10.1016/j.psychsport.2018.08.015

Power JD, Schlaggar BL, Lessov-Schlaggar CN et al (2013) Evidence for hubs in human functional brain networks. Neuron 79(4):798813. https://doi.org/10.1016/j.neuron.2013.07.035

Reuter-Lorenz PA, Park DC (2014) How does it stac up? Revisiting the scaffolding theory of aging and cognition. Neuropsychol Rev 24(3):355-370. https://doi.org/10.1007/s11065-014-9270-9

Salthouse TA (2011) Neuroanatomical substrates of age-related cognitive decline. Psychol Bull 137(5):753-784. https://doi. org/10.1037/a0023262

Schmitt A, Martin JA, Rojas S et al (2019) Effects of low- and highintensity exercise on emotional face processing: an fmri facematching study. Soc Cogn Affect Neurosci 14(6):657-665. https ://doi.org/10.1093/scan/nsz042

Sheffield JM, Repovs G, Harms MP et al (2015) Fronto-parietal and cingulo-opercular network integrity and cognition in health and schizophrenia. Neuropsychologia 73:82-93. https://doi. org/10.1016/j.neuropsychologia.2015.05.006

Shipley BA, Der G, Taylor MD et al (2006) Cognition and all-cause mortality across the entire adult age range: health and lifestyle survey. Psychosom Med 68(1):17-24. https://doi.org/10.1097/01. psy.0000195867.66643.0f

Smith JC, Nielson KA, Antuono P et al (2013) Semantic memory functional mri and cognitive function after exercise intervention in mild cognitive impairment. J Alzheimers Dis 37(1):197-215. https://doi.org/10.3233/jad-130467 
Stillman CM, Cohen J, Lehman ME et al (2016) Mediators of physical activity on neurocognitive function: a review at multiple levels of analysis. Front Hum Neurosci 10:626. https://doi.org/10.3389/ fnhum.2016.00626

Stillman CM, Esteban-Cornejo I, Brown B et al (2020) Effects of exercise on brain and cognition across age groups and health states. Trends Neurosci. https://doi.org/10.1016/j.tins.2020.04.010

Suwabe K, Byun K, Hyodo K et al (2018) Rapid stimulation of human dentate gyrus function with acute mild exercise. Proc Natl Acad Sci U S A 115(41):10487-10492. https://doi.org/10.1073/ pnas. 1805668115

Tulving E (1972) Episodic and semantic memory: organization of memory. Academic Press, Cambridge

Verburgh L, Konigs M, Scherder EJ et al (2014) Physical exercise and executive functions in preadolescent children, adolescents and young adults: a meta-analysis. Br J Sports Med 48(12):973-979. https://doi.org/10.1136/bjsports-2012-091441

Voelcker-Rehage C, Niemann C (2013) Structural and functional brain changes related to different types of physical activity across the life span. Neurosci Biobehav Rev. 37(9 Pt B):2268-2295. https ://doi.org/10.1016/j.neubiorev.2013.01.028

Voss MW, Soto C, Yoo S et al (2019) Exercise and hippocampal memory systems. Trends Cogn Sci 23(4):318-333. https://doi. org/10.1016/j.tics.2019.01.006

Wagner G, Herbsleb M, de la Cruz F et al (2017) Changes in fmri activation in anterior hippocampus and motor cortex during memory retrieval after an intense exercise intervention. Biol Psychol 124:65-78. https://doi.org/10.1016/j.biopsycho.2017.01.003

Wriessnegger SC, Steyrl D, Koschutnig K et al (2014) Short time sports exercise boosts motor imagery patterns: Implications of mental practice in rehabilitation programs. Front Hum Neurosci 8:469. https://doi.org/10.3389/fnhum.2014.00469

Wu MT, Tang PF, Goh JOS et al (2018) Task-switching performance improvements after tai chi chuan training are associated with greater prefrontal activation in older adults. Front Aging Neurosci 10:280. https://doi.org/10.3389/fnagi.2018.00280

Xue Y, Yang Y, Huang T (2019) Effects of chronic exercise interventions on executive function among children and adolescents: a systematic review with meta-analysis. Br J Sports Med 53(22):1397-1404. https://doi.org/10.1136/bjsports-2018-09982 5

Yan CG, Wang XD, Zuo XN et al (2016) Dpabi: data processing \& analysis for (resting-state) brain imaging. Neuroinformatics 14(3):339-351. https://doi.org/10.1007/s12021-016-9299-4

Yeo BTT, Krienen FM, Sepulcre J et al (2011) The organization of the human cerebral cortex estimated by intrinsic functional connectivity. J Neurophysiol 106(3):1125-1165. https://doi. org/10.1152/jn.00338.2011

Yu Q, Zou L, Kong Z et al (2020) Cognitive impact of calorie restriction: a narrative review. J Am Med Directors Assoc. https://doi. org/10.3390/brainsci9040087

Zhao W, Zimmermann K, Zhou X et al (2020) Impaired cognitive performance under psychosocial stress in cannabis- dependent men is associated with attenuated precuneus activity. J Psychiatry Neurosci 45(2):88-97. https://doi.org/10.1503/jpn.190039

Zheng G, Ye B, Zheng Y et al (2019) The effects of exercise on the structure of cognitive related brain regions: a meta-analysis of functional neuroimaging data. Int J Neurosci 129(4):406-415. https://doi.org/10.1080/00207454.2018.1508135

Publisher's Note Springer Nature remains neutral with regard to jurisdictional claims in published maps and institutional affiliations. 